\title{
Sex-specific differences in HPA axis activity in VLBW preterm newborns
}

\author{
Britt J van Keulen $11,2, *$, Michelle Romijn (101,2,*, Bibian van der Voorn ${ }^{3}$, Marita de Waard ${ }^{4}$, Michaela F Hartmann ${ }^{5}$, \\ Johannes B van Goudoever ${ }^{4}$, Stefan A Wudy ${ }^{5}$, Joost Rotteveel ${ }^{1}$ and Martijn J J Finken ${ }^{1,2}$ \\ 1'Department of Pediatric Endocrinology, Emma Children's Hospital, Amsterdam University Medical Centers, location VUmc, Amsterdam, The Netherlands \\ 2Department of Pediatrics, Amsterdam UMC, Vrije Universiteit Amsterdam, Amsterdam Reproduction \& Development Research Institute, de Boelelaan, \\ Amsterdam, The Netherlands \\ ${ }^{3}$ Department of Pediatric Endocrinology, Sophia Kinderziekenhuis, Erasmus MC, University Medical Center Rotterdam, Rotterdam, The Netherlands \\ ${ }^{4}$ Emma Children's Hospital, Amsterdam University Medical Centers, locations AMC and VUmc, Amsterdam, The Netherlands \\ ${ }^{5}$ Steroid Research and Mass Spectrometry Unit, Laboratory for Translational Hormone Analytics, Pediatric Endocrinology \& Diabetology, Center of Child \\ and Adolescent Medicine, Justus-Liebig-University, Giessen, Germany
}

Correspondence should be addressed to M Romijn: m.romijn1@amsterdamumc.nl

*(B J van Keulen and M Romijn contributed equally to this work)

\begin{abstract}
Objective: Sex-specific differences in hypothalamic-pituitary-adrenal axis activity might explain why male preterm infants are at higher risk of neonatal mortality and morbidity than their female counterparts. We examined whether male and female preterm infants differed in cortisol production and metabolism at 10 days post-partum.

Design and methods: This prospective study included 36 preterm born infants (18 boys) with a very low birth weight (VLBW) $(<1.500 \mathrm{~g})$. At 10 days postnatal age, urine was collected over a 4- to 6-h period. Glucocorticoid metabolites were measured using gas chromatography-mass spectrometry. Main outcome measures were: (1) cortisol excretion rate, (2) sum of all glucocorticoid metabolites, as an index of corticosteroid excretion rate, and (3) ratio of 11-OH/11-OXO metabolites, as an estimate of 11B-hydroxysteroid dehydrogenase (11B-HSD) activity. Differences between sexes, including interaction with Score of Neonatal Acute Physiology Perinatal Extension-II (SNAPPE II), sepsis and bronchopulmonary dysplasia (BPD), were assessed. Results: No differences between sexes were found for cortisol excretion rate, corticosteroid excretion rate or 11B-HSD activity. Interaction was observed between: sex and SNAPPE II score on 11B-HSD activity $(P=0.04)$ and sex and BPD on cortisol excretion rate $(P=0.04)$.

Conclusion: This study did not provide evidence for sex-specific differences in adrenocortical function in preterm VLBW infants on a group level. However, in an interaction model, sex differences became manifest under stressful circumstances. These patterns might provide clues for the male disadvantage in neonatal mortality and morbidity following preterm birth. However, due to the small sample size, the data should be seen as hypothesis generating.
\end{abstract}

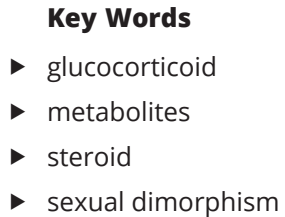

Endocrine Connections (2021) 10, 214-219

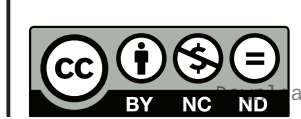

This work is licensed under a Creative Commons Attribution-NonCommercial-NoDerivatives 4.0 enternationad ticense ifica.com at 04/26/2023 12:12:34PM 


\section{Introduction}

Preterm birth has been associated with increased risks of mortality and morbidity (1). Studies among preterm infants showed that males have higher risks $(2,3,4)$ of morbidities like respiratory distress syndrome (RDS), lateonset sepsis (LOS), bronchopulmonary dysplasia (BPD) and intraventricular hemorrhage (IVH), and more often require invasive respiratory support $(2,4,5)$, than females. In childhood, male preterm infants had a greater odds of (major and minor) handicaps and had lower scores on tests of neurodevelopment than their female counterparts $(5,6)$.

Integrity of the hypothalamic-pituitary-adrenal (HPA) axis is crucial during critical illnesses. Among preterm infants, the HPA axis seems to be essential for blood pressure maintenance (7) and has been presumed to play a role in the dampening of the immune response (8). During their first weeks of life, many preterm infants fail to mount an adequate cortisol response for the degree of stress or illness $(9,10,11)$, termed relative adrenal insufficiency. After the second week of life, HPA axis has been shown to recover rapidly (12).

It has been suggested that sex-specific differences in HPA axis activity might explain part of the male disadvantage after preterm birth (13). Although sex differences in HPA axis activity have been postulated to emerge during puberty, recent evidence suggests that such differences are already present early in life $(14,15)$. However, little is known about sex-specific differences in cortisol production and metabolism in preterm newborns in their first weeks of life. Earlier research in a small sample of preterm infants $(n=5)$ suggested that boys, in contrast to girls, had no cortisol response to arterial hypotension (13).

We aimed to examine whether male and female preterm infants differ in cortisol production and metabolism as assessed by glucocorticoid metabolite excretion in urine, as a possible explanation for the sex differences in neonatal mortality and morbidity.

\section{Materials and methods}

\section{Participants}

This study is part of the early nutrition study, which is a double-blind randomized controlled trial (16) comparing donor mother's milk to preterm formula during the first 10 days of life as add-on to own mother's milk in preterm infants with very low birth weight (VLBW), that is, a birth weight $<1500 \mathrm{~g}$. VLBW infants admitted at one of six participating neonatal intensive care units (NICUs) throughout the Netherlands were enrolled between March 30, 2012 and August 17, 2014, as previously described (16). Exclusion criteria were maternal intoxications during pregnancy, major congenital anomalies or birth defects, congenital infections, perinatal asphyxia, and use of cow's milk prior to randomization. The study was approved by the medical ethical review committee VUmc, and written informed consent was obtained from all parents. For this specific study, only the infants who were admitted to the Amsterdam UMC location VUmc were included. Infants who were treated with interfering medication in the 5 days prior to sample collection (hydrocortisone, dexamethasone, ampicillin, neomycin, ketoconazole, miconazole and fluconazole $(17,18,19))$ were excluded. Written informed consent was obtained from all parents.

\section{Study protocol}

Urine collections were planned at the 10th day of life. For this purpose, the external genitals were covered using a latex patch with gauzes within it to minimize urine absorption by the diaper. Diapers were closed properly to minimize evaporation and/or leakage of urine. After a 4- to 6-h period, the gauzes were removed and placed in a tube that was subsequently stored at $-20^{\circ} \mathrm{C}$. In case of contamination by stools or low urine output, the procedure was repeated.

Clinical data were collected from participants, including the Score of Neonatal Acute Physiology Perinatal Extension II (SNAPPE II) (20), and the presence of bronchopulmonary dysplasia (BPD) and sepsis were assessed. The SNAPPE II score is an illness severity score that can be used to predict mortality during NICU admission (21). BPD was defined as the need for supplemental oxygen for at least 28 days, and its severity was rated based on the need for supplemental oxygen or respiratory support at 36 weeks postmenstrual age, according to international criteria (22). Sepsis was defined as one positive blood culture with non-coagulasenegative staphylococci or one positive blood culture with coagulase-negative staphylococci in combination with a C-reactive protein level greater than $10 \mathrm{mg} / \mathrm{L}$ within 2 days of blood culture or two positive blood cultures with coagulase-negative staphylococci drawn within 2 days (16).

\section{Laboratory analysis}

Urine specimens were stored at $-20^{\circ} \mathrm{C}$ and thawed only once just before analysis. After placement in a salivette,

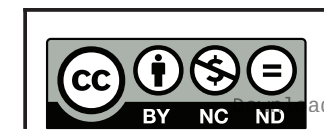

This work is licensed under a Creative Commons Attribution-NonCommercial-NoDerivatives 4.0 Internationad dicense ifica. com at 04/26/2023 12:12:34PM 
the pad was centrifuged at $1900 \boldsymbol{g}$ for $5 \mathrm{~min}$, enabling the extraction of urine.

Urinary steroids were determined using quantitative data produced by gas chromatography-mass spectrometry (GC-MS) analysis. Briefly, free and conjugated steroids were extracted from up to $5 \mathrm{~mL}$ of urine by solid phase extraction and the conjugates were enzymatically hydrolyzed. After recovery of hydrolyzed steroids by solid phase extraction, known amounts of internal standards (5A-androstane-3 A,17 A -diol, stigmasterol) were added to each extract before formation of methyloximetrimethylsilyl ethers. GC was performed using an Optima-1 fused silica column (Macherey-Nagel, Dueren, Germany) housed in an Agilent Technologies 6890 series GC that was directly interfaced to an Agilent Technologies 5975 inert XL mass selective detector. MS was run in the selected ion monitoring mode (23). All samples were measured in the same batch.

Measured steroids were: 6B-OH-cortisol (4-pregnene6b,11b,17a,21-tetrol-3,20-dione), 21A-dihydrocortisol (4-pregnene-11b,1 7a,20a, 21 -tetrol-3-one), cortisol (4-pregnene-11b,17a,21-triol-3,20-dione), tetrahydrocortisol (5b-pregnane-3a,11b,17a,21-tetrol-20one), allotetrahydrocortisol (5a-pregnane-3a,11b,17a,21tetrol-20-one), a-cortol (5b-pregnane-3a,11b,17a,20a,21pentol), b-cortol (5b-pregnane-3a,11b,17a,20b,21-pentol), tetrahydrocortison (5b-pregnane-3a,17a,21-triol-11,20dione), 6A-OH-tetrahydrocortisone (5b-pregnane-3a,6a, 17a,21-tetrol-11,20-dione), 1B-OH-tetrahydrocortisone (5b-pregnane-1b,3a,17a,21-tetrol-11,20-dione), a-cortolone (5b-pregnane-3a,17a,20a,21-tetrol-11-one), b-cortolone (5b-pregnane-3a,17a,20b,21-tetrol-11-one), 6A-OH-A-cortolone (5b-pregnane-3a,6a,17a,20a,21pentol-11-one), 6A-OH-B-cortolone (5b-pregnane3a,6b,17a,20b,21-pentol-11-one) and 1B-OH-B-cortolone (5b-pregnane-1b,3a, 17a,20b,21-pentol-11-one). Their concentrations were converted to microgram per kilogram body weight per day $(\mu \mathrm{g} / \mathrm{kg} /$ day $)$. Outcomes were: (1) cortisol excretion rate $(\mu \mathrm{g} / \mathrm{kg} / \mathrm{day})$, (2) the sum of all glucocorticoid metabolites or corticosteroid excretion rate $(\mu \mathrm{g} / \mathrm{kg} / \mathrm{day})$, and (3) the ratio of 11-hydroxy (11-OH)/11-oxoandrostenedione (11-OXO) metabolites, as an estimate of 11B-hydroxysteroid dehydrogenase (11B-HSD) activities.

\section{Statistical analysis}

All outcomes had non-normal distributions. We compared glucocorticoid parameters between sexes using the Mann-Withney U-test. Next, linear regression models were used to correct these analyses for gestational age and birth weight. For this purpose, outcomes were Ln transformed. Effect modification by sex of associations between morbidities and glucocorticoid parameters was tested by first including the variables sex (in male $=1$ and female $=0$ ) and SNAPPE II score or the presence of sepsis (total) or BPD (in which yes $=1$ and no $=0$ ) in the regression equation followed by the inclusion of their product. These analyses were corrected only for gestational age. A $P$-value of $<0.05$ was considered as statistically significant.

\section{Results}

Urine samples were available from 40 infants (20 boys and 20 girls). Four of them were excluded because of protocol violations related to the collection of urine or the use of interfering medication in the 5 days prior to sample collection, leaving 36 infants for analysis. Their characteristics are shown in Table 1. Girls and boys did not differ in birth weight, gestational age or disease risks. The majority of the sample collections ( $n=25,70 \%)$ started in the morning. Glucocorticoid parameters were no different between subjects who provided urine samples in the morning vs those who provided urine samples at other times of the day (data not shown).

\section{Sex differences}

Table 2 displays the glucocorticoid parameters by sex. There were no differences in cortisol excretion rate, corticosteroid excretion rate or 11B-HSD activity at 10 days post-partum between sexes. Linear regression analysis showed that sex differences remained absent after adjustment for gestational age and birth weight (data not shown).

\section{Interaction models}

Table 3 presents the interaction models of sex with SNAPPE II score, sepsis (total) or BPD on glucocorticoid parameters, corrected for gestational age. We observed an interaction between sex and SNAPPE II on 11B-HSD activity $(P=0.04)$, with the interconversion favoring cortisol in girls with higher SNAPPE II. A tendency toward a possible interaction was observed between sex and sepsis on corticosteroid excretion rate $(P=0.09)$, with girls with sepsis having a higher corticosteroid excretion rate compared to boys with sepsis.

This work is licensed under a Creative Commons Attribution-NonCommercial-NoDerivatives 4.0 International License ifica com at $04 / 26 / 2023 \quad 12: 12: 34 \mathrm{PM}$ 
Table 1 Perinatal characteristics of our sample.

\begin{tabular}{l}
\hline Characteristics \\
\hline Birth weight \\
g \\
S.D. score (24) \\
Gestational age \\
Weeks \\
Antenatal corticosteroids \\
Any dose \\
Full dose \\
SNAPPE Il score \\
Sepsis \\
Total \\
$<10$ days pp \\
Meningitis \\
Total \\
$<10$ days pp \\
NEC \\
Total \\
$<10$ d pp \\
BPD \\
Total \\
Mild \\
Moderate \\
Severe \\
Neonatal mortality \\
Total \\
Days pp \\
\hline
\end{tabular}

Boys $(n=18)$
$1047(829-1333)$
$0.00(-0.50$ to 0.73$)$
$27.0(26.0-29.0, \max 31.0)$
$5(28 \%)$
$11(61 \%)$
$5.0(0.0-14.5)$
$9(50 \%)$
$5(28 \%)$
$2(11 \%)$
$0(0 \%)$
$1(6 \%)$
$1(6 \%)$
$6(33 \%)$
3
1
2
$0(0 \%)$

\begin{tabular}{|c|c|}
\hline Girls $(n=18)$ & $P$-value \\
\hline $938(749-1160)$ & 0.19 \\
\hline $0.00(-0.75$ to 0.40$)$ & 0.57 \\
\hline $27.0(27.0-28.0, \max 29.0)$ & 0.67 \\
\hline $6(33 \%)$ & 0.34 \\
\hline $12(67 \%)$ & \\
\hline $10.0(0.0-28.3)$ & 0.33 \\
\hline $5(28 \%)$ & 0.31 \\
\hline $3(17 \%)$ & $>0.99$ \\
\hline $0(0 \%)$ & 0.49 \\
\hline $0(0 \%)$ & na \\
\hline $3(17 \%)$ & 0.60 \\
\hline $1(6 \%)$ & na \\
\hline $8(44 \%)$ & 0.73 \\
\hline 3 & \\
\hline 3 & \\
\hline 2 & \\
\hline $2(11 \%)$ & 0.49 \\
\hline $16-22$ & \\
\hline
\end{tabular}

Data are reported as median (interquartile range), $n$ (\%), or range. Continuous data were compared with independent samples T-tests and dichotomous variables with the Chi-square test or Fisher's exact test, as appropriate.

Furthermore, an interaction was observed between sex and BPD on cortisol excretion rate $(P=0.04)$, with boys with BPD having a higher cortisol excretion rate compared to girls with BPD. In addition, a tendency toward a possible interaction was observed for corticosteroid excretion rate $(P=0.08)$, with boys with BPD having a higher corticosteroid excretion rate compared to girls with BPD, and for 11B-HSD activity $(P=0.08)$, with the interconversion favoring cortisol in girls with BPD.

\section{Discussion}

In our study among preterm VLBW infants, we did not find evidence for sex differences in HPA axis activity on a group level. However, in an interaction model sex differences became manifest under stressful circumstances, reflected by high SNAPPE II score, sepsis and BPD, including differences in cortisol excretion rate, corticosteroid excretion rate and 11B-HSD activity.

A previous study among preterm infants showed that HPA axis activity differed between sexes depending on the timing of antenatal betamethasone treatment (25). Females born $<72 \mathrm{~h}$ of betamethasone exposure had higher urinary cortisol levels on day 1 , if exposed to perinatal stress, than males under similar circumstances. Our study suggests that sex differences persist during the second week of life, which supports our hypothesis that mortality and morbidity are higher in preterm boys partly due to a lower capability to secrete cortisol for the degree of stress.

Table 2 Glucocorticoid parameters by sex.

\begin{tabular}{l} 
Urinary glucocorticoid excretion \\
\hline Cortisol excretion rate $(\mu \mathrm{g} / \mathrm{kg} /$ day $)$ \\
Corticosteroid excretion rate $(\mu \mathrm{g} / \mathrm{kg} /$ day) \\
$11 \mathrm{~B}-\mathrm{HSD}$ activity
\end{tabular}

\begin{tabular}{c}
\hline Boys $(n=18)$ \\
\hline $550(117-758)$ \\
$33311(26280-65948)$ \\
$0.020(0.004-0.031)$ \\
\hline
\end{tabular}

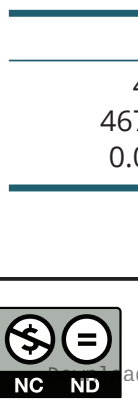

Girls $(n=18)$
$494(0-1091)$
$6733(15346-61254)$
$0.035(0.000-0.052)$

\begin{tabular}{c}
\hline P-value \\
\hline$>0.99$ \\
$>0.99$ \\
0.46 \\
\hline
\end{tabular}

Data are reported as median (interquartile range).

https://ec.bioscientifica.com https://doi.org/10.1530/EC-20-0587 (c) 2021 The authors Published by Bioscientifica Ltd
This work is licensed under a Creative Commons Attribution-NonCommercial-NoDerivatives 4.0 Internationab ficense.ifica . com at $04 / 26 / 2023$ 12:12:34PM 
Table 3 Interaction of sex with SNAPPE II score, sepsis and BPD on glucocorticoid parameters.

\begin{tabular}{|c|c|}
\hline Dependent variable & Interaction mode \\
\hline Ln cortisol excretion rate ( $\mu \mathrm{g} / \mathrm{kg} / \mathrm{day})$ & $\begin{array}{l}\text { Sex*SNAPPE II } \\
\text { Sex* Sepsis } \\
\text { Sex*BPD }\end{array}$ \\
\hline Ln corticosteroid excretion rate ( $\mu \mathrm{g} / \mathrm{kg} / \mathrm{day})$ & $\begin{array}{l}\text { Sex*SNAPPE II } \\
\text { Sex* Sepsis } \\
\text { Sex*BPD }\end{array}$ \\
\hline Ln 11B-HSD activity & $\begin{array}{l}\text { Sex*SNAPPE II } \\
\text { Sex*sepsis } \\
\text { Sex*BPD }\end{array}$ \\
\hline
\end{tabular}

\begin{tabular}{c}
\hline Beta $(95 \% \mathrm{Cl})$ \\
\hline $0.007(-0.06 ; 0.07)$ \\
$0.397(-1.03 ; 1.82)$ \\
$-1.477(-2.87 ;-0.08)$ \\
$-0.008(-0.05 ; 0.36)$ \\
$0.954(-0.17 ; 2.08)$ \\
$-1.008(-2.16 ; 0.14)$ \\
$-0.090(-0.18 ; 0.00)$ \\
$-1.888(-4.13 ; 0.35)$ \\
$-2.092(-4.41 ; 0.23)$ \\
\hline
\end{tabular}

\begin{tabular}{|c|c|}
\hline Exp Beta & $P$-value \\
\hline 1.01 & 0.82 \\
\hline 1.49 & 0.57 \\
\hline 0.23 & 0.04 \\
\hline 0.99 & 0.71 \\
\hline 2.60 & 0.09 \\
\hline 0.36 & 0.08 \\
\hline 0.91 & 0.04 \\
\hline 0.15 & 0.10 \\
\hline 0.12 & 0.08 \\
\hline
\end{tabular}

Contrary to our expectation, we found that boys who developed BPD had an elevation in both cortisol excretion rate and corticosteroid excretion rate at 10 days post-partum as compared to girls who developed BPD. Earlier research in VLBW infants demonstrated that lower serum cortisol concentrations in the first week of life predisposed to chronic lung disease (26). In general, preterm boys are more prone to develop (severe) BPD than preterm girls $(27,28)$. Therefore, we expected that boys who went on to develop BPD would have a lower instead of a higher corticosteroid excretion rate at 10 days post-partum than girls developing BPD. On the other hand, we found that the balance between the activities of 11B-HSD isozymes was more at the side of cortisone in boys than in girls developing BPD, implying that the higher cortisol production in these boys is partly offset by an increased elimination in them. However, our results should be balanced against the small size of our sample. In our study, girls with BPD were overrepresented.

Our study has several strengths. This is the first study exploring sex differences in cortisol production and metabolism in the second week of life in preterm VLBW infants as an explanation for the sex differences in neonatal mortality and morbidity as observed after preterm birth. Cortisol metabolites were measured with GC-MS, which enabled the calculation of both cortisol production and the interconversion with cortisone. Our study also has its limitations. First of all, our study had a small sample size, which increases the likelihood of chance findings. Therefore, replication of our findings in a larger, independent sample seems warranted. Secondly, urine samples were only collected at 10 days post-partum. Preferably, urine samples would have been collected at multiple days during the first weeks of life for a more precise assessment of HPA axis development. Thirdly, we had no information on the timing of antenatal corticosteroid treatment. Finally, for practical reasons related to the NICU setting we were not able to collect $24-\mathrm{h}$ urine. However, young infants have not yet developed an adult-like circadian rhythm (29).

\section{Conclusion}

This study did not provide evidence for sex-specific differences in cortisol production and metabolism in preterm VLBW infants on a group level. However, in an interaction model, sex differences became manifest under stressful circumstances. These patterns might offer an explanation for the sex-specific differences in neonatal mortality and morbidity as observed after preterm birth. However, due to the small sample size, the data should be seen as hypothesis generating.

\section{Declaration of interest}

The authors declare that there is no conflict of interest that could be perceived as prejudicing the impartiality of the research reported.

\section{Funding}

This work did not receive any specific grant from any funding agency in the public, commercial, or not-for-profit sector.

\section{References}

1 Harrison MS \& Goldenberg RL. Global burden of prematurity. Seminars in Fetal and Neonatal Medicine 201621 74-79. (https://doi. org/10.1016/j.siny.2015.12.007)

2 Boghossian NS, Geraci M, Edwards EM \& Horbar JD. Sex differences in mortality and morbidity of infants born at less than 30 weeks gestation. Pediatrics 2018142 e20182352. (https://doi.org/10.1542/ peds.2018-2352)

3 Costeloe K, Hennessy E, Gibson AT, Marlow N \& Wilkinson AR. The EPICure study: outcomes to discharge from hospital for infants born at the threshold of viability. Pediatrics 2000106 659-671. (https:// doi.org/10.1542/peds.106.4.659)

4 Townsel CD, Emmer SF, Campbell WA \& Hussain N. Gender differences in respiratory morbidity and mortality of preterm neonates. Frontiers in Pediatrics 20175 6. (https://doi.org/10.3389/ fped.2017.00006) (c) 2021 The authors Published by Bioscientifica Ltd
This work is licensed under a Creative Commons Attribution-NonCommercial-NoDerivatives 4.0 International License . 
5 Skiold B, Alexandrou G, Padilla N, Blennow M, Vollmer B \& Aden U. Sex differences in outcome and associations with neonatal brain morphology in extremely preterm children. Journal of Pediatrics 2014 164 1012-1018. (https://doi.org/10.1016/j.jpeds.2013.12.051)

6 Verloove-Vanhorick SP, Veen S, Ens-Dokkum MH, Schreuder AM, Brand R \& Ruys JH. Sex difference in disability and handicap at five years of age in children born at very short gestation. Pediatrics 1994 $93576-579$

7 Ng PC, Lee CH, Lam CW, Ma KC, Fok TF, Chan IH \& Wong E. Transient adrenocortical insufficiency of prematurity and systemic hypotension in very low birthweight infants. Archives of Disease in Childhood: Fetal and Neonatal Edition 200489 F119-F126. (https:// doi.org/10.1136/adc.2002.021972)

8 Nicolaides NC, Kyratzi E, Lamprokostopoulou A, Chrousos GP $\&$ Charmandari E. Stress, the stress system and the role of glucocorticoids. Neuroimmunomodulation 201522 6-19. (https://doi. org/10.1159/000362736)

9 Finken MJJ, van der Voorn B, Hollanders JJ, Ruys CA, de Waard M, van Goudoever JB \& Rotteveel J. Programming of the hypothalamuspituitary-adrenal axis by very preterm birth. Annals of Nutrition and Metabolism 2017 70 170-174. (https://doi.org/10.1159/000456040)

10 Fernandez EF \& Watterberg KL. Relative adrenal insufficiency in the preterm and term infant. Journal of Perinatology 200929 (Supplement 2) S44-S49. (https://doi.org/10.1038/jp.2009.24)

11 Heckmann M, Wudy SA, Haack D \& Pohlandt F. Serum cortisol concentrations in ill preterm infants less than 30 weeks gestational age. Acta Paediatrica 200089 1098-1103. (https://doi. org/10.1080/713794576)

$12 \mathrm{Ng}$ PC. Effect of stress on the hypothalamic-pituitary-adrenal axis in the fetus and newborn. Journal of Pediatrics 2011158 (Supplement) e41-e43. (https://doi.org/10.1016/j.jpeds.2010.11.012)

13 Heckmann M, Hartmann MF, Kampschulte B, Gack H, Bodeker RH, Gortner L \& Wudy SA. Assessing cortisol production in preterm infants: do not dispose of the nappies. Pediatric Research $2005 \mathbf{5 7}$ 412-418. (https://doi.org/10.1203/01.PDR.0000153947.51642.C1)

14 Panagiotakopoulos L \& Neigh GN. Development of the HPA axis: where and when do sex differences manifest? Frontiers in Neuroendocrinology 201435 285-302. (https://doi.org/10.1016/j. yfrne.2014.03.002)

15 van der Voorn B, Hollanders JJ, Ket JCF, Rotteveel J \& Finken MJJ. Gender-specific differences in hypothalamus-pituitary-adrenal axis activity during childhood: a systematic review and meta-analysis. Biology of Sex Differences 20178 3. (https://doi.org/10.1186/s13293016-0123-5)

16 Corpeleijn WE, de Waard M, Christmann V, van Goudoever JB, Jansen-van der Weide MC, Kooi EM, Koper JF, Kouwenhoven SM, Lafeber HN, Mank E, et al. Effect of donor milk on severe infections and mortality in very low-birth-weight infants: the early nutrition study randomized clinical trial. JAMA Pediatrics $2016170654-661$. (https://doi.org/10.1001/jamapediatrics.2016.0183)

17 Adlercreutz H, Martin F, Jarvenpaa P \& Fotsis T. Steroid absorption and enterohepatic recycling. Contraception 197920 201-223. (https://doi.org/10.1016/0010-7824(79)90094-5)
18 Back DJ, Breckenridge AM, Crawford FE, Cross KJ, Orme ML, Percival A \& Rowe PH. Reduction of the enterohepatic circulation of norethisterone by antibiotics in the rat: correlation with changes in the gut flora. Journal of Steroid Biochemistry 198013 95-100. (https:// doi.org/10.1016/0022-4731(80)90118-1)

19 Engelhardt D, Dorr G, Jaspers C \& Knorr D. Ketoconazole blocks cortisol secretion in man by inhibition of adrenal 11betahydroxylase. Klinische Wochenschrift 198563 607-612. (https://doi. org/10.1007/BF01733014)

20 Richardson DK, Corcoran JD, Escobar GJ \& Lee SK. SNAP-II and SNAPPE-II: simplified newborn illness severity and mortality risk scores. Journal of Pediatrics 2001 138 92-100. (https://doi. org/10.1067/mpd.2001.109608)

21 Harsha SS, Archana BR. SNAPPE-II (score for neonatal acute physiology with perinatal extension-II) in predicting mortality and morbidity in NICU. Journal of Clinical and Diagnostic Research 20159 SC10-SC12. (https://doi.org/10.7860/JCDR/2015/14848.6677)

22 Jobe AH \& Bancalari E. Bronchopulmonary dysplasia. American Journal of Respiratory and Critical Care Medicine 2001163 1723-1729. (https://doi.org/10.1164/ajrccm.163.7.2011060)

23 Heckmann M, Hartmann MF, Kampschulte B, Gack H, Bodeker RH, Gortner L \& Wudy SA. Cortisol production rates in preterm infants in relation to growth and illness: a noninvasive prospective study using gas chromatography-mass spectrometry. Journal of Clinical Endocrinology and Metabolism 200590 5737-5742. (https://doi. org/10.1210/jc.2005-0870)

24 Fenton TR \& Kim JH. A systematic review and meta-analysis to revise the Fenton growth chart for preterm infants. BMC Pediatrics 201313 59. (https://doi.org/10.1186/1471-2431-13-59)

25 Stark MJ, Wright IM \& Clifton VL. Sex-specific alterations in placental 11beta-hydroxysteroid dehydrogenase 2 activity and early postnatal clinical course following antenatal betamethasone. American Journal of Physiology: Regulatory, Integrative and Comparative Physiology 2009297 R510-R514. (https://doi.org/10.1152/ ajpregu.00175.2009)

26 Watterberg KL, Scott SM, Backstrom C, Gifford KL \& Cook KL. Links between early adrenal function and respiratory outcome in preterm infants: airway inflammation and patent ductus arteriosus. Pediatrics 2000105 320-324. (https://doi.org/10.1542/ peds.105.2.320

27 Zysman-Colman Z, Tremblay GM, Bandeali S \& Landry JS Bronchopulmonary dysplasia - trends over three decades. Paediatrics and Child Health 201318 86-90. (https://doi.org/10.1093/pch/18.2.86)

28 Binet ME, Bujold E, Lefebvre F, Tremblay Y, Piedboeuf B \& Canadian Neonatal Network ${ }^{\mathrm{TM}}$. Role of gender in morbidity and mortality of extremely premature neonates. American Journal of Perinatology 2012 29 159-166. (https://doi.org/10.1055/s-0031-1284225)

29 Hollanders JJ, van der Voorn B, de Goede P, Toorop AA, Dijkstra LR, Honig A, Rotteveel J, Dolman KM, Kalsbeek A \& Finken MJJ. Biphasic glucocorticoid rhythm in one month old infants: reflection of a developing HPA-axis? Journal of Clinical Endocrinology and Metabolism 2020105 dgz089. (https://doi.org/10.1210/clinem/ dgz089)

Received in final form 3 December 2020

Accepted 20 January 2021

Accepted Manuscript published online 23 January 2021 https://ec.bioscientifica.com https://doi.org/10.1530/EC-20-0587 (c) 2021 The authors Published by Bioscientifica Ltd
This work is licensed under a Creative Commons Attribution-NonCommercial-NoDerivatives 4.0 International License ${ }_{i}$ ica com at $04 / 26 / 202312: 12: 34 \mathrm{PM}$ 